\title{
Kinetic mechanism of competitive adsorption of disperse dye and anionic dye on fly ash
}

\author{
D. Sun $\cdot$ X. Zhang $\cdot$ Y. Wu $\cdot$ T. Liu
}

Received: 12 February 2012/Revised: 10 June 2012/Accepted: 25 September 2012/Published online: 1 November 2012 (c) CEERS, IAU 2012

\begin{abstract}
The adsorption behavior of four anionic dyes and one disperse dye in single solution and binary solutions on fly ash was investigated in order to elucidate the effect of competitive adsorption on the kinetics. The experimental findings showed that adsorption equilibriums of four anionic dyes were reached within 50 min either in the single solution or in binary mixtures. Competitive adsorption increased the time of attaining equilibrium of disperse dye. Desorption of dyes suggested the predominant adsorption mechanisms, that is, chemisorption for anionic dyes and physisorption for disperse dye. For the binary mixtures, the anionic dyes could be adsorbed preferentially on fly ash at the first stage. Second-order kinetic models fitted better to the equilibrium data of all dyes in the single solution as well as in the binary mixtures. The maximum rate constant of intraparticle diffusion and the minimum external mass transfer coefficient was found for disperse dye both in single and in binary solutions. The intraparticle diffusion constants and external mass transfer coefficients of the four anionic dyes in binary solution are similar to those obtained in single solution. The Biot number confirmed that the intraparticle diffusion was the rate-limiting step in the dye sorption process.
\end{abstract}

D. Sun $(\bowtie) \cdot X$. Zhang $\cdot$ T. Liu

College of Chemistry and Chemical Engineering,

Qingdao University, Qingdao 266071, China

e-mail: luckysds@163.com

Y. Wu

Qingdao Sub-administration, Administrative Departments for

Yellow River Diversion to Qingdao Project of Shandong

Province, Qingdao 266071, China
Keywords Binary solutions - Desorption . External mass transfer - Second-order kinetic modal . Intraparticle diffusion - Wastewater

\section{Introduction}

Synthetic dyes have been increasingly used in textile, leather, food processing, dyeing, cosmetics, and so on. Wastewater streaming from these industries contains unused dyes (about 8-20\% of the total pollution load due to incomplete exhaustion of the dye) (Mukherjee et al. 1999), which causes adverse effects on aquatic environment. Because the dyes in low concentration give water undesirable color (Wong et al. 2003), they reduce sunlight penetration into water and then affect photosynthesis of aquatic organisms. Most dyes with a complex aromatic molecular structure are considered to be non-oxidizable substances by traditional biological and physical treatment (Mane et al. 2007). As a result, the conventional techniques of wastewater treatment on the basis of biological oxygen demand removal are largely ineffective in removing colored textile dyes from effluent. Adsorption process, therefore, is an attractive and effective alternative treatment for dye removal from wastewater.

Fly ash (FA) is a by-product produced during the combustion of coal in the electricity generation process. Although fly ash has also been used effectively for building materials, soil amendment, and fillers, it is unlikely that these applications will result in the reuse of all the fly ash generated. Great efforts are therefore being made to explore other applications prior to disposal. Since fly ash is enriched with $\mathrm{SiO}_{2}$ and contains a portion of unburned carbon, this waste possesses a potentiality of a low-cost adsorbent to remove various hazardous materials from 
wastewater (Dizge et al. 2008; Hsu 2008; Janoš and Buchtová 2003; Kao et al. 2000; Mohan et al. 2002; Ramakrishna and Viraraghavan 1997; Wang et al. 2005; Wang and Wu 2006). Recently, the technical feasibilities were reviewed by Ahmaruzzaman (2010) and Saka et al. (2012).

Numerous investigations have been reported on the adsorption of single component dye by various adsorbents. However, due to complexity of the textile effluent and the variability of the dyeing process little successes have been reported in using this technique as a full-scale process to decolorize textile wastewater (Al-Degs et al. 2007; Nouri et al. 2002). Since many industrial effluents contain a mixtures of several dyes, the study of multi-component adsorption presents a major challenge compared to the single component adsorption. This work concerns the single and binary adsorption of non-ionic dyes (Disperse red 74) and anionic dye (Acid blue 193, Acid black 1, Reactive blue 4 and Reactive blue 171) by fly ash.

\section{Materials and methods}

\section{Adsorbents and characterization}

Raw coal fly ash used in this study was provided by a fullscale power plant in China, which was collected at the electrostatic precipitator. The chemical compositions of the sample were measured using a NK-09 inductively coupled plasma atomic emission spectroscopy (Beijing Zhuochuan Electronic Technology), which mainly contained $\mathrm{SiO}_{2}$ (47.2\%), $\mathrm{Al}_{2} \mathrm{O}_{3}(24.8 \%), \mathrm{Fe}_{2} \mathrm{O}_{3}(15.9 \%)$, and $\mathrm{CaO}$ $(4.9 \%)$ (obtained from the plant). The loss of ignition (LOI) was $3.81 \%$, which measured by a standard combustion method.

Raw fly ash dried at $105^{\circ} \mathrm{C}$ overnight was separated manually by shaking stainless steel mesh screens with the opening of standard numbers of 160 and 200. Fly ash particles with size ranging from 75 to $96 \mu \mathrm{m}$ were pretreated in a furnace at $350{ }^{\circ} \mathrm{C}$ for $30 \mathrm{~min}$, and kept in a desiccator for further study. The fly ash density was $1,838 \mathrm{~kg} \mathrm{~m}^{-3}$, which was determined by the displacement method. The mean particle size $(85.5 \mu \mathrm{m})$ was calculated by the average value of the two sizes of sieve opening. Prior to their use, the adsorbents were oven-dried at $105^{\circ} \mathrm{C}$ for $2 \mathrm{~h}$ to eliminate traces of moisture.

The surface area and total pore volume of the FA were measured through $\mathrm{N}_{2}$ adsorption at $-196{ }^{\circ} \mathrm{C}$ using a TRISTAR-3000 surface area and porosity analyzer (Micromeritics). The specific surface area and pore volume of the FA was found to be $9.84 \mathrm{~m}^{2} \mathrm{~g}^{-1}$ and $0.023 \mathrm{~cm}^{3} \mathrm{~g}^{-1}$, respectively. $\mathrm{pH}$ of zero charge $\left(\mathrm{pH}_{\mathrm{pzc}}=8.4\right)$ of the samples was determined using $\mathrm{pH}$ drift method by a
PHS-3C pH meter (Shanghai Precision \& Scientific Instrument Co. LTD) (Fariaa et al. 2004).

\section{Adsorbates}

The adsorbates in this study include one non-ionic dye, Disperse Red 74 (DR74), and four anionic dyes, Acid Black 1 (AB1), Acid Blue193 (AB193), Reactive blue 4 (RB4), and Reactive Blue 171 (RB171). The anionic dyes were supplied by Dystar and the disperse dye was purchased from Baodao Chemical Engineering Co. Ltd. All dyes were employed without further purification. Their stereo-chemical structures were optimized by ChemSketch 12.0 (Advanced Chemistry Development, Toronto, Canada) and displayed in Fig. 1. Molecular weight and dimension data were obtained using ChemSketch 12.0. Table 1 compared some selected chemical properties of these dyes.

The synthetic wastewaters were prepared by dissolving dyestuffs in de-ionized water to produce a stock solution of $1 \mathrm{~g} \mathrm{~L}^{-1}$. The initial $\mathrm{pH}$ values of synthetic wastewaters were in the range 5.6-6.3, and the $\mathrm{pH}$ values of residue solution were kept in 5.8-7.4 in order to eliminate the effect of dye self-aggregate (Mall et al. 2005). For batch study, aqueous solutions of these dyes were prepared from stock solutions in de-ionized water. The UV-Visible spectrum of each dye solution was previously determined and identified the maximum absorption wavelength $\left(\lambda_{\max }\right)$.

\section{Kinetic adsorption study}

Batch experiments were carried out to measure the competitive adsorption characteristics between non-ionic dye and anionic dyes on FA. A predetermined amount of the fly ash sample was added to $100 \mathrm{~mL}$ of dye solution. The mixture was stirred with mechanical agitator $(150 \mathrm{rpm})$ for various times to determined the equilibrium time at $25^{\circ} \mathrm{C}$. After stirring, the suspensions were separated by filtering. Dye solutions included five single component systems, DR74, RB4, RB171, AB1, and AB193, and four binary component systems, DR74/RB4, DR74/RB171, DR74/ AB1, and DR74/AB193. For the binary component systems, all solutions were prepared with solutions of equal mass concentrations. The initial concentration of each dye was kept $100 \mathrm{mg} \mathrm{L}^{-1}$ either in single solutions or in binary systems. All adsorption data reported in this paper were the average values of three runs.

The residual concentration of dye solution was determined using a UV-2102PC UV-visible spectrometer (Unicol Instrument Co., Ltd). For the single dye systems, concentrations were measured using a calibration curve prepared at the corresponding maximum wavelength. For the binary systems, the value of the unknown dye 
Fig. 1 Stereo-chemical structure of dyes. a Disperse Red 74, b Reactive blue 4, c Reactive Blue 171, d Acid Blue193, e Acid Black 1

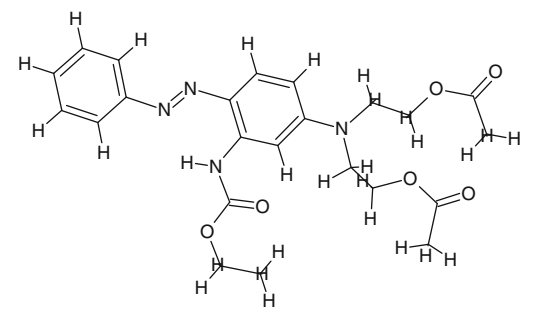

(a)<smiles>O=C1c2ccccc2C(=O)c2c1cccc2S(=O)(=O)[O-]</smiles>

(b)

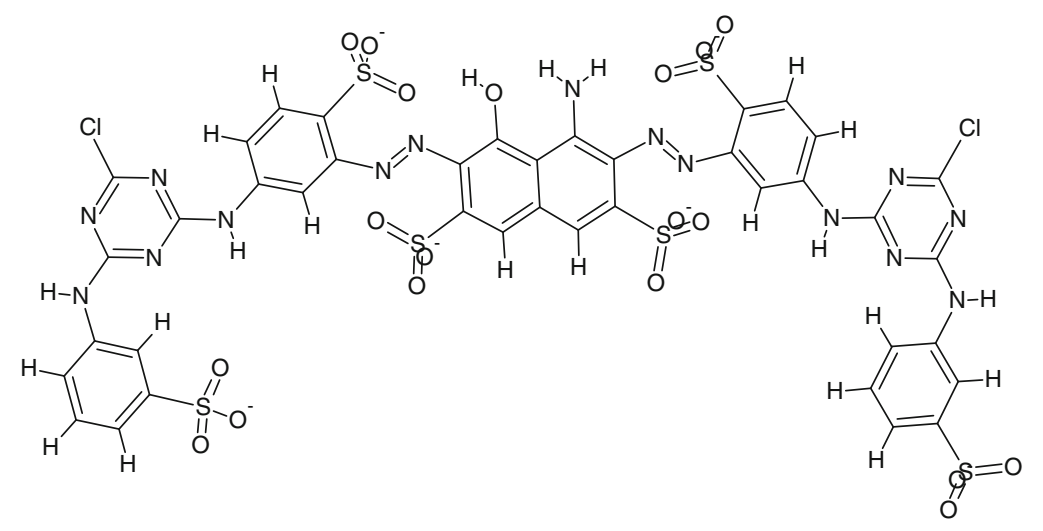

(c)

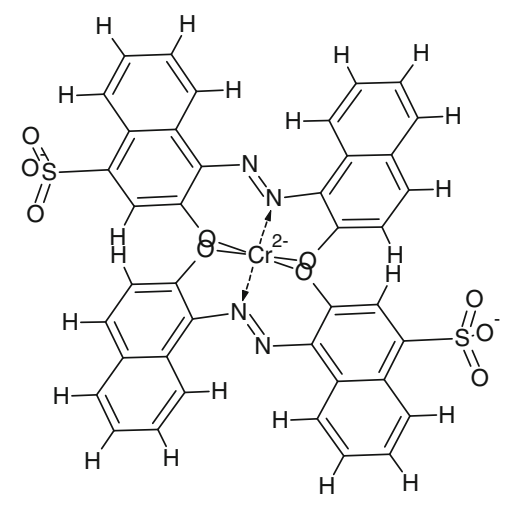

(d)<smiles>[B][Se]c1cc2cc(S(=O)(=O)[Se])c(N=Nc3ccc([N+](=O)[O-])cc3)c(O)c2c(N)c1N=Nc1ccccc1</smiles>

(e)

Table 1 Chemical properties of the dyes

${ }^{a}$ Does not include associated sodium ions

\begin{tabular}{|c|c|c|c|c|c|}
\hline Property & DR74 & RB4 & RB171 & $\mathrm{AB} 1$ & AB193 \\
\hline Molecular weight ${ }^{\mathrm{a}}$ & 456.5 & 620.4 & $1,281.0$ & 570.5 & 836.8 \\
\hline Width $(\AA)$ & 18.042 & 15.087 & 31.986 & 21.658 & 15.889 \\
\hline Depth $(\AA)$ & 9.436 & 10.605 & 14.086 & 6.192 & 13.734 \\
\hline Thickness $(\AA)$ & 3.042 & 2.593 & 6.207 & 4.751 & 3.644 \\
\hline$\lambda_{\max }(\mathrm{nm})$ & 522 & 600 & 602 & 614 & 592 \\
\hline Number of ionizable group & 0 & 2 & 6 & 2 & 2 \\
\hline Percent of ionizable group $(\%)^{\mathrm{a}}$ & 0 & 15.47 & 22.95 & 16.82 & 11.47 \\
\hline
\end{tabular}


concentrations could be determined by solving simultaneous linear equation 1 and 2 (Porter et al. 1999).

$A_{1}=\varepsilon_{11} b C_{1}+\varepsilon_{21} b C_{2}$

$A_{2}=\varepsilon_{12} b C_{1}+\varepsilon_{22} b C_{2}$

where $A_{1}$ and $A_{2}$ are the absorbance at the maximum wavelength of dye 1 and $2\left(\lambda_{\max , 1}\right.$ and $\left.\lambda_{\max , 2}\right)$, respectively. $\varepsilon_{11}$ and $\varepsilon_{12}$ are the absorption coefficients of dye 1 at $\lambda_{\max , 1}$ and $\lambda_{\max , 2}, \varepsilon_{21}$ and $\varepsilon_{22}$ are the absorption coefficients of dye 2 at $\lambda_{\text {max, } 1}$ and $\lambda_{\text {max,2 }}$, respectively. $b(\mathrm{~cm})$ is the length of light path. $C_{1}$ and $C_{2}\left(\mathrm{~mol} \mathrm{~L}^{-1}\right)$ are concentrations of dye 1 and 2. The method described by Al-Degs et al. (2007) was used to estimate the absorption coefficient. The absorption coefficient for each dye was determined from the absorbance measurements of the dye at specific concentration. The slope of the linear regression about the concentration absorbance curves gave the value of the absorption coefficient for each dye at its wavelength of maximum absorption and at the wavelength of maximum absorption for the other dyes.

\section{Results and discussions}

Adsorption of dyes in the single and binary solution

Industry wastewater was normally a mixture of many compounds rather than a single one. The competitive adsorption of two dyes on fly ash was investigated using binary premature dye solutions. Figure 2 illustrated the mass of dye adsorbed on FA in single and binary solution. For the single solution, the adsorption of each dye was quite rapid in the first $50 \mathrm{~min}$, and then a plateau formed after $50 \mathrm{~min}$ of contact. For the binary systems, the adsorption of disperse dye and anionic dye were a simultaneous process. However, the competitive adsorption showed clearly the interaction between dyes. It could be seen that the adsorption of all anionic dye (acid dyes and reactive dye) reached equilibrium within $50 \mathrm{~min}$ in binary solution, but the equilibrium time of disperse dye was longer than $50 \mathrm{~min}$. It indicated that the adsorption rate of disperse dye (DR74) was affected apparently by the existence of the anionic dyes during the competitive adsorption while the rate of anionic dyes was almost unaffected by DR74 at all.

Table 2 presented the adsorption data of the single and binary systems. The adsorptive capacity of DR74 decreased from $3.899 \mathrm{mg} \mathrm{g}^{-1}$ in single solution to 2.681 , 3.378 , 3.244, and $3.163 \mathrm{mg} \mathrm{g}^{-1}$ in DR74/RB4, DR74/ RB171, DR74/AB1, and DR74/AB193 systems, respectively. Similar results could be seen for all anionic dyes. The reduction of equilibrium adsorption of individual dye in binary mixtures could be attributed to the competitive effects. However, the reduction extent varied in different binary systems. For disperse dye, the lowest adsorption capacity was found in DR74/RB4 solutions, and decreased about $31.3 \%$ when compared to adsorption from the single solution. The highest competition between DR74 and RB4
Fig. 2 Adsorption dyes on fly ash in the single and binary solutions
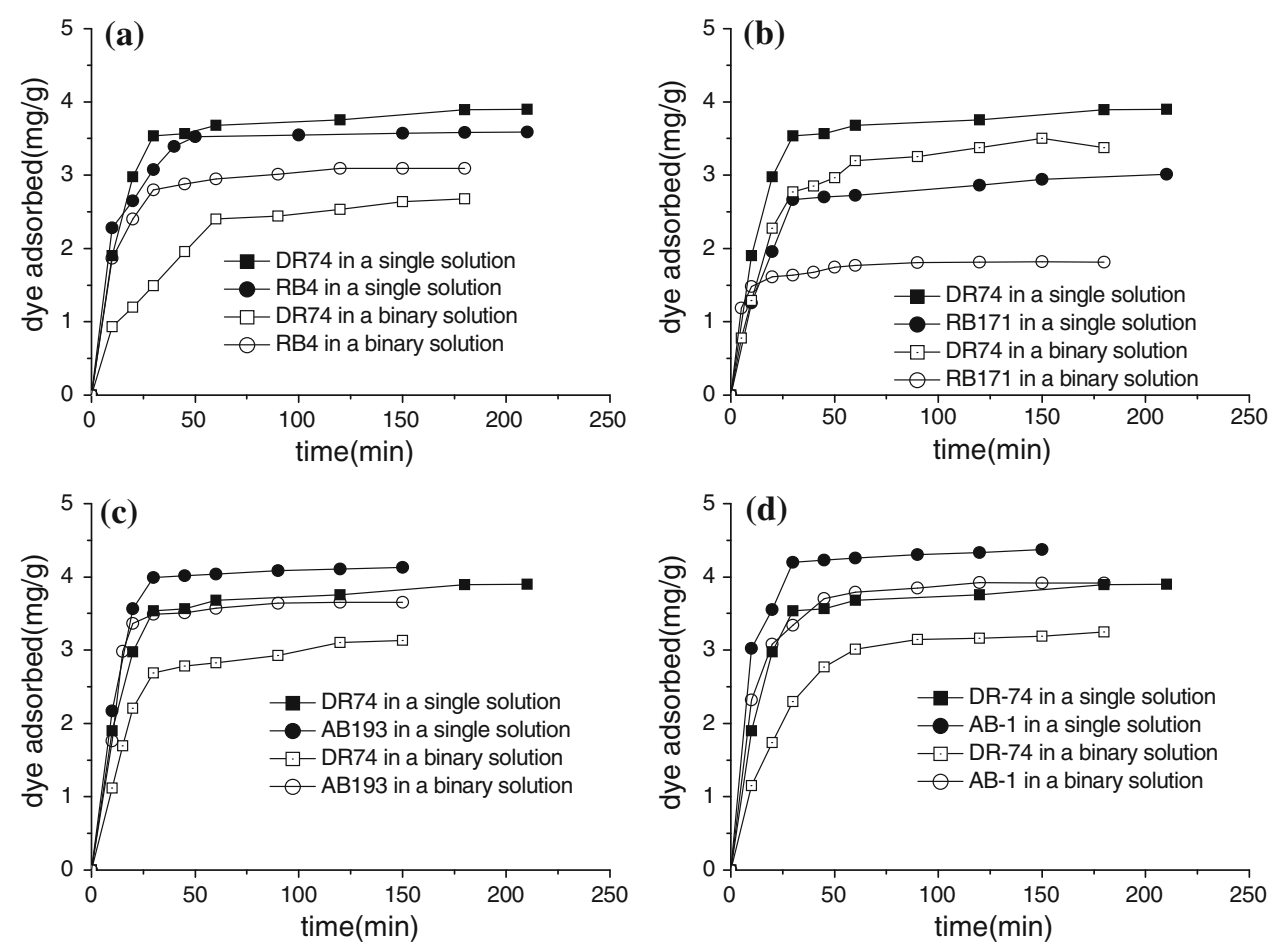
Table 2 Equilibrium adsorption amount of single and binary systems

\begin{tabular}{|c|c|c|c|c|c|c|}
\hline \multirow[t]{2}{*}{ Single systems } & \multirow[t]{2}{*}{$q\left(\mathrm{mg} \mathrm{g}^{-1}\right)$} & \multirow[t]{2}{*}{ Binary systems } & \multicolumn{2}{|c|}{$q\left(\mathrm{mg} \mathrm{g}^{-1)}\right.$} & \multicolumn{2}{|c|}{ Reduction extent (\%) } \\
\hline & & & DR74 & Other dye & DR74 & Other dye \\
\hline DR74 & 3.899 & & & & & \\
\hline RB4 & 3.601 & DR74/RB4 & 2.681 & 3.093 & 31.3 & 13.9 \\
\hline RB171 & 3.011 & DR74/RB171 & 3.378 & 1.185 & 11.4 & 39.7 \\
\hline AB1 & 4.375 & DR74/AB1 & 3.244 & 3.920 & 16.8 & 10.4 \\
\hline AB193 & 4.132 & DR74/AB193 & 3.163 & 3.652 & 19.6 & 11.6 \\
\hline
\end{tabular}

could be the result of the similar molecular dimension data (Table 1) of the two dyes. The data also indicated a high degree of competition between DR74 and RB171 as the reduction in RB171 adsorption capacity was $39.7 \%$ in the binary systems. An explanation could be given as disperse dye with no ionizable group was easily adsorbed in the large micropores near the surface. This resulted in the reduction in size of the larger pores, and then hindered the adsorption of RB171, which has a larger molecular volume. Acid dye and disperse dye have similarity affinity for fly ash, as the reduction in adsorption capacity was about $10-20 \%$ in the binary systems.

It could also be inferred from Table 2 that the total mass of adsorbed dyes in binary systems was higher than that in single solution. For example, the maximum adsorption values of 3.899 and $4.375 \mathrm{mg} \mathrm{g}^{-1}$ for DR74 and AB1, respectively, in the single solution while the total adsorbed mass of the two dyes in the binary system was $7.164 \mathrm{mg} \mathrm{g}^{-1}(3.224+3.920$, respectively). These results suggested that more active adsorption sites of FA were occupied in binary mixtures. The increment of total adsorption in binary solution was also reported in adsorption of dyes on activated carbon (Al-Degs et al. 2007; Walker and Weatherley 2000).

Desorption of dyes in the single and binary solution

In order to determine the predominant adsorption mechanisms, adsorbent samples were extracted after equilibrium. About $1.0 \mathrm{~g}$ of adsorbent was added to $100 \mathrm{~mL}$ of $\mathrm{N}, \mathrm{N}$ dimethylformamide and the mixtures were stirred at 150 rpm for 3 days. Samples were separated by centrifugation and dyes were recycled. The recovery efficiency of dyes was calculated and showed in Table 3. For disperse dye, the recovery efficiency exceeded $90 \%$ in single solution and was found to be from 86.06 to $91.67 \%$ in binary mixtures. As comparison, the values of four anionic dyes were in range 35.85-48.82 \% in single solution and $4.05-8.05 \%$ in binary systems. These results revealed the uptake of dyes on FA was the combined action of the chemisorption and physisorption. However, the predominant adsorption mechanisms were chemisorption for anionic dyes and physisorption for disperse dye (Noroozi et al. 2008). This chemisorption mechanism of anionic dye may be due to complexation between the negatively charged groups $\left(\mathrm{D}-\mathrm{SO}^{3-}\right)$ in anionic dyes and positively charged $\mathrm{SiO}_{2}$ or $\mathrm{Al}_{2} \mathrm{O}_{3}$ groups on the surface of $\mathrm{FA}\left(\mathrm{pH}_{\mathrm{pzc}}=8.4\right)$ (Bulut et al. 2008; Sun et al. 2010).

\section{Adsorption kinetics}

Adsorption kinetics show the dependence on the physical and chemical characteristics of the adsorbent material and adsorbate species. From Fig. 2, the adsorption process included two stages both in the single solution and in binary mixtures: the first rapid stage and the later slower stage. Using the experimental data, the adsorption rate of dye at different stage was calculated using the simple rate expression $r=\mathrm{d} C / \mathrm{d} t$ by differential method. The initial adsorption rate at the two stages was given in Table 4. It could be observed that the adsorption rate of dye in rapid stage was about 5-15 times greater than those in the slower stage for the single solution, with one exception for RB171 in binary mixtures. For single solution, the maximum
Table 3 Recovery efficiency of the dyes from used adsorbents

\begin{tabular}{lllll}
\hline Single system & Recovery efficiency (\%) & Binary systems & \multicolumn{2}{l}{ Recovery efficiency (\%) } \\
\cline { 4 - 5 } & & & DR74 & Other dye \\
\hline DR74 & 91.35 & & 88.15 & 4.05 \\
RB4 & 35.85 & DR74/RB4 & 5.81 \\
RB171 & 42.17 & DR74/RB171 & 91.67 & 6.77 \\
AB1 & 43.35 & DR74/AB1 & 86.06 & 8.05 \\
AB193 & 48.82 & DR74/AB193 & 88.75 & \\
\hline
\end{tabular}


Table 4 The initial adsorption rate at the rapid and slow stages in initial dye concentration of $100 \mathrm{mg} \mathrm{L}^{-1}$

\begin{tabular}{llllll}
\hline $\begin{array}{l}\text { Single } \\
\text { system }\end{array}$ & $\begin{array}{l}r_{\text {Rapid }} \\
\left(\mathrm{mg} \mathrm{g}^{-1} \mathrm{~min}^{-1}\right)\end{array}$ & $\begin{array}{l}r_{\text {Slow }} \\
\left(\mathrm{mg} \mathrm{g}^{-1} \mathrm{~min}^{-1}\right)\end{array}$ & $\begin{array}{l}\text { Binary } \\
\text { systems }\end{array}$ & $\begin{array}{l}r_{\text {Rapid }} \\
\left(\mathrm{mg} \mathrm{g}^{-1} \mathrm{~min}^{-1}\right)\end{array}$ & $\begin{array}{l}r_{\text {Slow }} \\
\left(\mathrm{mg} \mathrm{g}^{-1} \mathrm{~min}^{-1}\right)\end{array}$ \\
\hline DR74 & 4.75 & 0.72 & & & \\
RB4 & 5.84 & 0.93 & DR74/RB4 & $3.50 / 5.62$ & $0.58 / 0.85$ \\
RB171 & 7.67 & 0.45 & DR74/RB171 & $3.96 / 5.95$ & $0.31 / 0.16$ \\
AB1 & 7.56 & 0.83 & DR74/AB1 & $2.88 / 5.80$ & $0.26 / 0.65$ \\
AB193 & 5.45 & 0.65 & DR74/AB193 & $2.84 / 4.85$ & $0.29 / 0.68$ \\
\hline
\end{tabular}

adsorption rate in the rapid stage was observed to be $7.67 \mathrm{mg} \mathrm{g}^{-1} \mathrm{~min}^{-1}$ for RB171, while the minimum value was $4.75 \mathrm{mg} \mathrm{g}^{-1} \mathrm{~min}^{-1}$ for DB74. For binary mixtures, the adsorption rate of anionic dyes in rapid stage was higher than that of DR74, which resulted in the preferential adsorption of anionic dye. This phenomenon could also be seen in Fig. 2 that the mass of anionic dye adsorbed on FA was higher than that of disperse dye (DR74) at the first 20 times. In the slow stage, the adsorption rate of RB171 was the minimum one either in single solution or in binary mixtures, which may be explained by the fact that the largest volume of RB171 hindered the pore diffusion.

In order to understand the comprehensive adsorption mechanisms and interactions of the two dyes onto FA, the pseudo-first and second-order kinetic adsorption models were employed. The optimal modal was considered base on two indicators: correlation coefficient $\left(r^{2}\right)$ and root mean square error (RMSE). The correlation coefficient was frequently used to decide whether the model represents correctly the experimental data. RMSE was defined as:

$\mathrm{RMSE}=\sqrt{\frac{\sum_{1}^{N}\left(q_{\mathrm{exp}}-q_{\mathrm{cal}}\right)^{2}}{N}}$

where $q_{\text {exp }}$ and $q_{\text {cal }}$ are the experimentally measured and modal prediction for the amount of dyes adsorbed, respectively. Smaller RMSE represents the equation can predict more accurately the experiment results.
The pseudo-first and second-order kinetic models are the most common model to study the adsorption kinetics of dyes on FA. The simplified linear form of first-order model was given by the Eq. (4) (Srivastava et al. 2006; Wasewar et al. 2008; Zhu et al. 2012).

$\ln \frac{\left(q_{\mathrm{e}}-q\right)}{q_{\mathrm{e}}}=-k_{1} t$

where $q\left(\mathrm{mg} \mathrm{g}^{-1}\right)$ is the amount of material adsorbed at time $t, q_{\mathrm{e}}\left(\mathrm{mg} \mathrm{g}^{-1}\right)$ is the adsorption capacity at equilibrium, $k_{1}\left(\mathrm{~min}^{-1}\right)$ represents the rate constant of the firstorder model. When $\operatorname{Ln}\left(\left(q_{\mathrm{e}}-q\right) / q_{\mathrm{e}}\right)$ was plotted against $t$ (plot not shown), Eq. 2 showed a straight line passing through the origin (Srivastava et al. 2006). Batch dynamic parameters were obtained using linear regression analysis (MATLAB 7.5) and showed in Table 5.

The second-order kinetic equation was defined as follows (Ho and McKay 1999; Srivastava et al. 2006):

$q=\frac{k_{2} q_{\mathrm{e}} t}{1+k_{2} t}$

where $k_{2}\left(\mathrm{~g} \mathrm{mg}^{-1} \mathrm{~min}^{-1}\right)$ is the rate constant of the secondorder model. Batch dynamic parameters were obtained using linear regression analysis (MATLAB 7.5). Table 5 showed the adsorption parameters and the two indicators using each of the modal. The performances of kinetic models tested were comparable based on the correlation coefficients and RMSEs for each dye. For the five dyes in

Table 5 The first and second-order adsorption rate constants at initial dye concentration of $100 \mathrm{mg} \mathrm{L}^{-1}$

\begin{tabular}{|c|c|c|c|c|c|c|}
\hline & \multicolumn{3}{|c|}{ First-order kinetic model } & \multicolumn{3}{|c|}{ Second-order kinetic model } \\
\hline & $k_{1}\left(\min ^{-1}\right)$ & $r^{2}$ & RMSE & $k_{2}\left(\mathrm{~g} \mathrm{mg}^{-1} \min ^{-1}\right)$ & $r^{2}$ & RMSE \\
\hline DR74 & 0.038 & 0.968 & 0.478 & 0.114 & 0.989 & 0.165 \\
\hline RB4 & 0.033 & 0.929 & 0.641 & 0.151 & 0.991 & 0.103 \\
\hline RB171 & 0.028 & 0.957 & 0.570 & 0.085 & 0.984 & 0.151 \\
\hline $\mathrm{AB} 1$ & 0.054 & 0.922 & 0.506 & 0.205 & 0.993 & 0.109 \\
\hline AB193 & 0.052 & 0.949 & 0.419 & 0.181 & 0.981 & 0.226 \\
\hline DR74/RB4 & $0.028 / 0.041$ & $0.983 / 0.962$ & $0.130 / 0.392$ & $0.036 / 0.146$ & $0.985 / 0.997$ & $0.105 / 0.057$ \\
\hline DR74/RB171 & $0.032 / 0.049$ & $0.963 / 0.955$ & $0.321 / 0.367$ & $0.065 / 0.369$ & $0.987 / 0.997$ & $0.127 / 0.024$ \\
\hline DR74/AB1 & $0.034 / 0.041$ & $0.967 / 0.953$ & $0.151 / 0.479$ & $0.052 / 0.137$ & $0.997 / 0.989$ & $0.117 / 0.062$ \\
\hline DR74/AB193 & $0.038 / 0.063$ & $0.961 / 0.971$ & $0.298 / 0.378$ & $0.070 / 0.148$ & $0.978 / 0.981$ & $0.164 / 0.261$ \\
\hline
\end{tabular}


single system, correlation coefficients for the first rate modal were in the range $0.922-0.968$, while these values for the second rate modal were bigger than 0.98. At the same time, higher RMSE values $(\mathrm{RMSE}=0.419-0.641$ ) were obtained with the first-order kinetics. These results suggested pseudo second-order modal was applicable to the adsorption kinetics. Similar kinetic results were found for every dye in binary systems, even if there were competitive adsorptions between dyes. According to the higher $r^{2}$ and the lower RMSEs, the pseudo second-order showed better fitted to the kinetic data of dyes on the FA in the mixtures solution, which indicated that the adsorption kinetic mechanism of dyes was unaffected by the competitive adsorption processes. However, the second-order kinetic rate constants of each dye decreased in binary system in contrast to those in single solution with only one exception for RB171. The values of the rate for RB171 increased from $0.086 \mathrm{~g} \mathrm{mg}^{-1} \mathrm{~min}^{-1}$ in single solution to $0.369 \mathrm{~g} \mathrm{mg}^{-1} \mathrm{~min}^{-1}$ in binary solution.

Adsorption rate controlling mechanism

Adsorption is a transient process involving some sort of Fick diffusion in both the fluid and adsorbent phases. It was important to identify the types of rate controlling mechanism. A number of mechanisms were suggested to control the adsorption rate of dye-adsorbent systems. Of the mechanisms mentioned above, external film and pore diffusion were most likely to prevail during dye adsorption onto fly ash.

According to previous studies (Kumar and Porkodi 2007; Wang and Li 2007), the intraparticle diffusion plot represented a multilinearity which characterized the two or more steps involved in the sorption process. The intraparticle diffusion model is defined as follows:

$q=k_{\mathrm{i}} t^{0.5}$

where $k_{\mathrm{i}}\left(\mathrm{mg} \mathrm{g}^{-1} \mathrm{~min}^{-0.5}\right)$ is the intraparticle rate constant. Figure 3 described the plot of $q$ versus $t^{0.5}$ for dyes on FA. It was observed that there were two linear portions, indicating two adsorption stages. The initial sharper portion of the plot indicated the external surface adsorption or instantaneous adsorption stage while the second linear portion was due to intraparticle or pore diffusion. The kinetic parameters calculated from the diffusion kinetic models were shown in Table 6. As seen, a higher rate constant of intraparticle diffusion was for DR74 either in single solution or in binary solution. The values of DR74 increased in binary mixtures, although adsorption capacities at equilibrium decreased as compared to those in single system. However, the rate constants of the four anionic dyes were similar to those obtained in single solution. It was slightly lower for AB1 and a little higher for RB171.
In order to understand the adsorption rate controlling mechanism, a mathematical modal was used to gain the intraparticle diffusion coefficient. Intraparticle diffusion, $D\left(\mathrm{~cm}^{2} \mathrm{~s}^{-1}\right)$, the sum of pore and surface diffusion, may simply be calculated from the following equation (Khraisheh et al. 2002).

$-\log \left(1-\left(\frac{q}{q_{e}}\right)^{2}\right)=\frac{4 \pi D}{2.3 d^{2}} t$

where $d(\mu \mathrm{m})$ is the mean particle diameter. Table 6 showed the calculated results and revealed that the values of the internal diffusion coefficient fall well within the magnitudes reported in literature (Chazopoulos et al. 1993), specifically for chemisorption systems $\left(10^{-5}\right.$ to $10^{-13} \mathrm{~cm}^{2} \mathrm{~s}^{-1}$ ).

As illustrated in Fig. 3, the external mass of dye particles at initial time periods was significant for adsorption process. The external diffusion model (Findon et al. 1993; Rengaraj and Moon 2002) assumes that the concentration at the adsorbent surface tends to zero and the intraparticle diffusion is negligible at early times of contact. The change in concentration of adsorbates with respect to the time is related by the following equation (Kumar and Porkodi 2007):

$-\frac{\mathrm{d} C}{\mathrm{~d} t}=k_{\mathrm{f}} \frac{A}{V}\left(C_{\mathrm{t}}-C_{\mathrm{e}}\right)$

where $C_{\mathrm{t}}, C_{\mathrm{e}}, A / V$, and $t$ are the concentration $\left(\mathrm{mg} \mathrm{L}^{-1}\right)$ at time $t$ and at equilibrium, the total interfacial area of the particles $\left(\mathrm{cm}^{2}\right)$ to the total solution volume (L) and adsorption time, respectively. $A / V$ is expressed as Eq. (9) (Dizge et al. 2008).

$\frac{A}{V}=\frac{3 m}{\rho d}$

where $m\left(\mathrm{~g} \mathrm{~cm}^{-3}\right)$ is the adsorbent dosage and $\rho$ is the apparent density of the adsorbent $\left(\mathrm{g} \mathrm{cm}^{-3}\right)$. Using the initial conditions (i.e., $C_{\mathrm{t}}=C_{0}$ and $C_{\mathrm{e}}=0$ at $t=0$ ), therefore

$\left[\frac{\mathrm{d} C / C_{0}}{\mathrm{~d} t}\right]_{t=0}=-k_{\mathrm{f}} \frac{3 m}{\rho d}$

The external diffusion coefficient $k_{\mathrm{f}}$ can be obtained using differential calculation in MATLAB 7.5. The calculated external mass transfer coefficient, $k_{\mathrm{f}}\left(\mathrm{cm} \mathrm{s}^{-1}\right)$, for the adsorption of dye on FA was also given in Table 6 . The external mass transfer coefficient of DR74 in single solution and binary mixtures was the minimum one. The value decreased from $1.65 \times 10^{-4} \mathrm{~cm} \mathrm{~s}^{-1}$ in single solution to $0.98 \times 10^{-4}-1.29 \times 10^{-4} \mathrm{~cm} \mathrm{~s}^{-1}$ in binary mixtures. The external mass transfer coefficients of the four anionic dyes are slightly lower in binary solution as compared to the single dye systems. By comparing the 
Fig. 3 Intraparticle diffusion kinetics for dyes on fly ash
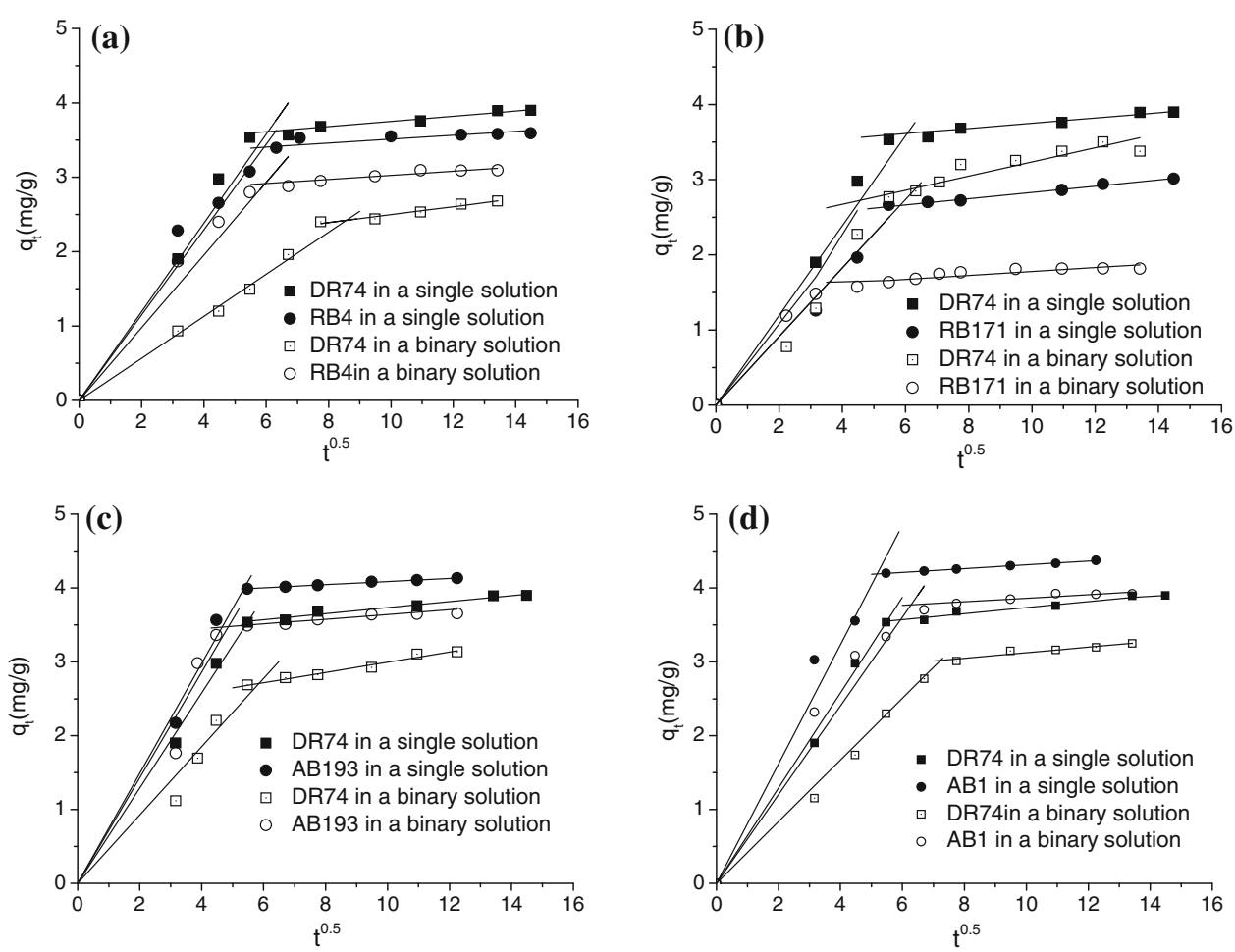

Table 6 The kinetic rate constants of dyes on fly ash

\begin{tabular}{lllllll}
\hline & $\begin{array}{l}k_{\mathrm{i}} \\
\left(\mathrm{mg} \mathrm{g}^{-1} \mathrm{~min}^{-0.5}\right)\end{array}$ & $r^{2}$ & $\begin{array}{l}D \times 10^{8} \\
\left(\mathrm{~cm}^{2} \mathrm{~s}^{-1}\right)\end{array}$ & $r^{2}$ & $\begin{array}{l}k_{\mathrm{f}} \times 10^{4} \\
\left(\mathrm{~cm} \mathrm{~s}^{-1}\right)\end{array}$ & $B_{\mathrm{N}}$ \\
\hline DR74 & 0.034 & 0.978 & 0.33 & 0.968 & 1.65 & 217 \\
RB4 & 0.027 & 0.952 & 0.28 & 0.942 & 2.05 & 319 \\
RB171 & 0.022 & 0.995 & 0.23 & 0.965 & 2.42 & 263 \\
AB1 & 0.026 & 0.997 & 0.30 & 0.930 & 2.36 & 150 \\
AB193 & 0.021 & 0.995 & 0.39 & 0.957 & 1.79 & 195 \\
DR74/RB4 & $0.053 / 0.027$ & $0.981 / 0.920$ & $0.22 / 0.32$ & $0.976 / 0.987$ & $0.98 / 2.01$ & $188 / 265$ \\
DR74/RB171 & $0.094 / 0.026$ & $0.942 / 0.929$ & $0.22 / 0.28$ & $0.935 / 0.976$ & $1.39 / 2.24$ & $475 / 292$ \\
DR74/AB1 & $0.038 / 0.024$ & $0.952 / 0.923$ & $0.28 / 0.34$ & $0.963 / 0.959$ & $1.09 / 2.02$ & $357 / 251$ \\
DR74/AB193 & $0.069 / 0.021$ & $0.981 / 0.922$ & $0.28 / 0.46$ & $0.943 / 0.989$ & $1.02 / 1.62$ & $156 / 149$ \\
\hline
\end{tabular}

values of $k_{\mathrm{i}}$ and $k_{\mathrm{f}}$, it could be concluded that the competition adsorption in binary solutions unaffected the adsorption kinetic behavior of anionic dyes, but it improved the intraparticle rate and decreased the external diffusion coefficient of disperse dye in binary solution.

When the external and intraparticle diffusion coefficients are calculated for a given adsorption system, the Biot number can then be estimated from the Eq. (11) (Apiratikul et al. 2011; Queka and Al-Duri 2007):

$B_{\mathrm{N}}=k_{\mathrm{f}} \frac{r}{D}=k_{\mathrm{f}} \frac{d}{2 D}$

The Biot number gives a criterion for the predominance of surface diffusion against external diffusion. As seen in Table 6, all Biot number obtained from all adsorption system was higher than 100, which suggested that adsorption of dyes on FA was mainly controlled by intraparticle diffusion mechanism (Guibal et al. 1998; Khraisheh et al. 2002).

\section{Conclusion}

The competitive adsorption of disperse dye and anionic dye on fly ash was investigated. The following conclusions could be derived from the present study.

1. Adsorption equilibriums were reached within $50 \mathrm{~min}$ for all dyes used in the single solution. In binary solutions, the competitive adsorption unaffected the equilibrium time of all anionic dye (acid dyes and reactive dye), but increased the time of attaining 
equilibrium of disperse dye. Desorption of dyes suggested the predominant adsorption mechanisms were chemisorption for anionic dyes and physisorption for disperse dye.

2. Adsorption process included the first rapid stage and the later slower stage. For binary mixtures, the anionic dyes could be adsorbed preferentially on FA at the first stage. The initial adsorption rate of dye in rapid stage was about 5-15 times greater than those in the slower stage with one exception for RB171 in binary mixtures. The second-order kinetic models fitted better to the equilibrium data of all dyes either for the single solution or for the binary mixtures.

3. The maximum intraparticle diffusion rate constant and the minimum external mass transfer coefficient was found for disperse dye both in single and in binary solution. The intraparticle diffusion constants and external mass transfer coefficients of the four anionic dyes in the binary solution are similar to those obtained in single solution. The Biot number confirmed the intraparticle diffusion was the rate-limiting step in dye sorption process.

Acknowledgments The authors wish to acknowledge the financial support from Open Foundation of Chemical Engineering Subject (Qingdao University of Science and Technology, China) and Ministry of Water Resources Special Funds for Scientific Research on Public Causes (200901063).

\section{References}

Ahmaruzzaman M (2010) A review on the utilization of fly ash. Prog Energy Combust Sci 36(3):327-363

Al-Degs Y, Khraisheh MAM, Allen SJ, Ahmad MN, Walker GM (2007) Competitive adsorption of reactive dyes from solution: equilibrium isotherm studies in single and multisolute systems. Chem Eng J 128(2-3):163-167

Apiratikul R, Madacha V, Pavasant P (2011) Kinetic and mass transfer analyses of metal biosorption by Caulerpa lentillifera. Desalination 278(1-3):303-311

Bulut E, Özacar M, Şengil ÍA (2008) Equilibrium and kinetic data and process design for adsorption of Congo Red onto bentonite. J Hazard Mater 154(1-3):613-622

Chazopoulos D, Varma A, Irvine RL (1993) Activated carbon adsorption and desorption of toluene in the aqueous phase. AIChE J 39(12):2027-2041

Dizge N, Aydiner C, Demirbas E, Kobya M, Kara S (2008) Adsorption of reactive dyes from aqueous solutions by fly ash: kinetic and equilibrium studies. J Hazard Mater 150(3):737-746

Fariaa PCC, Örfäo JJM, Pereira MFR (2004) Adsorption of anionic and cationic dyes on activated carbons with different surface chemistries. Water Res 38(8):2043-2052

Findon A, McKay G, Blair HS (1993) Transport studies for the sorption of copper ions by Chitosan. J Environ Sci Health A 28(1):173-185

Guibal E, Milot C, Tobin JM (1998) Metal anion sorption by chitosan beads: equilibrium and kinetic studies. Ind Eng Chem Res 37(4):1454-1463
Ho YS, McKay G (1999) Pseudo-second order model for sorption processes. Process Biochem 34(5):451-465

Hsu TJ (2008) Adsorption of an acid dye onto coal fly ash. Fuel 87(13-14):3040-3045

Janoš P, Buchtová H, Rýznarová M (2003) Sorption of dyes from aqueous solutions onto fly ash. Water Res 37(20):4938-4944

Kao PC, Tzeng JH, Huang TL (2000) Removal of chlorophenols from aqueous solution by fly ash. J Hazard Mater 76(2-3):237-249

Khraisheh MAM, Al-Degs YS, Allen SJ, Ahmad MN (2002) Elucidation of controlling steps of reactive dye adsorption on activated carbon. Ind Eng Chem Res 41(6):1651-1657

Kumar KV, Porkodi K (2007) Mass transfer, kinetics and equilibrium studies for the biosorption of methylene blue using Paspalum notatum. J Hazard Mater 146(1-2):214-226

Mall ID, Srivastava VC, Agarwal NK, Mishra IM (2005) Removal of congo red from aqueous solution by bagasse fly ash and activated carbon: kinetic study and equilibrium isotherm analyses. Chemosphere 61(4):492-501

Mane VS, Mall ID, Srivastava VC (2007) Kinetic and equilibrium isotherm studies for the adsorptive removal of Brilliant Green dye from aqueous solution by rice husk ash. J Environ Manage 84(4):390-400

Mohan D, Singh KP, Singh G, Kumar K (2002) Removal of dyes from wastewater using fly ash, a low-cost adsorbent. Ind Eng Chem Res 41(15):3688-3695

Mukherjee AK, Gupta B, Chowdhury SMS (1999) Separation of dyes from cotton dyeing effluent using cationic polyelectrolytes. Am Dyest Rep 88(2):25-28

Noroozi B, Sorial GA, Bahrami H, Arami M (2008) Adsorption of binary mixtures of cationic dyes. Dyes Pigment 76(3):784-791

Nouri S, Haghseresht F, Lu GQM (2002) Comparison of adsorption capacity of $p$-cresol and $p$-nitrophenol by activated carbon in single and double solute. Adsorption 8(3):215-223

Porter JF, McKay G, Choy KH (1999) The prediction of sorption from a binary mixture of acidic dyes using single- and mixedisotherm variants of the ideal adsorbed solute theory. Chem Eng Sci 54(24):5863-5885

Queka SY, Al-Duri B (2007) Application of film-pore diffusion model for the adsorption of metal ions on coir in a fixed-bed column. Chem Eng Proc 46(5):477-485

Ramakrishna KR, Viraraghavan T (1997) Dye removal using low cost adsorbents. Water Sci Technol 36(2-3):189-196

Rengaraj S, Moon SH (2002) Kinetic of adsorption of Co(II) removal from water and wastewater by ion exchange resins. Water Res 36(7):1783-1793

Saka C, Şahin Ö, Küçük MM (2012) Applications on agricultural and forest waste adsorbents for the removal of lead (II) from contaminated waters. Int J Environ Sci Technol 9(2):379-394

Srivastava VC, Swamy MM, Mall ID, Prasad B, Mishra IM (2006) Adsorptive removal of phenol by bagasse fly ash and activated carbon: equilibrium, kinetics and thermodynamics. Colloids Surf A Physicochem Eng Aspects 272(1-2):89-104

Sun D, Zhang X, Wu Y, Liu X (2010) Adsorption of anionic dyes from aqueous solution on fly ash. J Hazard Mater 181(1-3): 335-342

Walker GM, Weatherley LR (2000) Prediction of multisolute dye adsorption on activated carbon. Trans IchemE B 9(3): 219-223

Wang S, Li H (2007) Kinetic modelling and mechanism of dye adsorption on unburned carbon. Dyes Pigment 72(3):308-314

Wang SB, Wu H (2006) Environmental-benign utilization of fly ash as low-cost adsorbents. J Hazard Mater 136(3):482-501

Wang S, Boyjoo Y, Choueib A (2005) A comparative study of dye removal using fly ash treated by different methods. Chemosphere 60(10):1401-1407 
Wasewar KL, Atif M, Prasad B, Mishra IM (2008) Adsorption of zinc using tea factory waste: kinetics, equilibrium and thermodynamics. Clean-Soil Air Water 36(3):320-329

Wong YC, Szeto YS, Cheung WH, McKay G (2003) Equilibrium studies for acid dye adsorption onto Chitosan. Langmuir 19(19):7888-7894
Zhu Y, Zhang H, Zeng H, Liang M, Lu R (2012) Adsorption of chromium (VI) from aqueous solution by the iron(III)-impregnated sorbent prepared from sugarcane bagasse. Int J Environ Sci Technol 9(3):463-472 